\title{
Aligned Across Difference: Structural Injustice, Sex Work, and Human Trafficking
}

\section{Corinne Schwarz, Emily J. Kennedy, Hannah Britton}

Feminist scholars and activists engage in meaningful, contentious debates about the relationships among sex, gender, power, and society. One of the most recent iterations of these arguments reinscribes the pleasure of sex positivity and danger of patriarchal exploitation onto new subjects: sex work and human trafficking. This paper brings together two separate empirically based research projects, one working with sex workers and the other working with members of the anti-trafficking community. As scholars working across these topics, we provide new normative propositions that may bridge these different approaches to resilience, survival,

danger, and risk. We find that the real threat identified by our participants was the wide reach of the carceral state onto migrating, working, and trafficked bodies. Our projects find unexpected commonality in shared perceptions of pleasure, agency, and danger among sex workers, human trafficking survivors, and service providers working with trafficked persons. Current debates ignore the lived experiences of our participants, who attempt to find pleasure in context-specific agency and survival, and who locate danger in the looming forces of the security state, criminality, and structural inequalities.

Keywords: agency / carceral feminism / human trafficking / inequalities / sex work 


\section{Introduction}

Feminist debates surrounding sex work and human trafficking are notoriously contentious, with a binary approach that sees pro-sex work and antihuman trafficking ideologies as incompatible. This article enters the debate among feminists working to end sexual violence, address human trafficking, and ensure the rights and agency of sex workers. These debates have pitted feminist against feminist as they try to create more livable lives for people globally. The stakes are high because the manifestations of this conflict have become entrenched in legislation, incarceration, and deportation—structures that affect real people's material conditions and lived experiences. The battle lines are drawn on these bodies attempting to survive deeply constrained environments, to imagine new forms of freedom and pleasure, and to escape coercion, violence, poverty, and abuse.

Consider those in the United States thought to be most vulnerable to exploitation and trafficking. The United States currently has 402,378 children in foster care, 14.5 million people in poverty under the age of 18 , and an estimated 2.5 million homeless youth $-20-40$ percent of whom are LGBTQ youth (US Department of Health and Human Services 2014; US Census Current Population Survey 2016; National Center on Family Homelessness 2014). Homeless LGBTQ youth are at even greater risks for trafficking, sexual violence, abuse, and suicide (National Coalition for the Homeless 2009). Consider also the impact of the carceral state. In the United States, 56,575 persons were arrested for prostitution in 2012 (Bureau of Justice 2012), and 360,000-400,000 persons were deported from 2009 to 2014 (US Department of Homeland Security 2015). 
This paper speaks across the contentious divide between sex work and human trafficking research. As members of the interdisciplinary Institute for Policy \& Social Research (IPSR) at the University of Kansas, we were able to bring our projects into conversation to explore how structural injustices and carceral violence affect marginalized populations. These are not parallel projects; methodologically, we draw from two different samples of sex workers and antitrafficking service providers, respectively. These interviews were conducted in different geographic regions at different times and had distinct research objectives. Even with these differences, both projects define sex work as commercial sexual activities exchanged for money and human trafficking as any commercial activity induced by fraud, force, or coercion. Even if it is a constrained choice, sex work is potentially agentive, while human trafficking involves having that agency compromised or even excised completely. Additionally, the themes and topics we encountered in our projects fit in a larger conversation about agency, vulnerability, and exploitation, and both directly address the growing divide between anti-trafficking activists and sex work advocates. This paper emerges from this normative conversation, indicating that these two camps share far more than either has acknowledged.

Neither of our projects sought out trafficked persons, as interviewing this population of survivors could be potentially retraumatizing, especially as trafficked persons are called upon to tell and retell their stories within the judicial system and research studies. Even with these goals, both research teams encountered trafficked persons in our participant pool, demonstrating the scope of trafficking across disparate populations: two sex workers interviewed in Kennedy's project experienced fraud; one service provider in Britton and Schwarz's study self-identified as a trafficking survivor. 
We argue that, coerced or not, lives are harmed — and made less livable — by structural injustice, anti-immigration rhetoric, deepening poverty, incarceration, and defunding the welfare state. Taking a cue from Butler (2004), we argue that these factors create the climate for lives to be made less livable: to be compromised, devalued, subject to violence, and removed from political legibility. We illuminate the statistics with rich qualitative data that begins to answer the call for accuracy about human trafficking and sex work. We assert the conflict between abolitionist and autonomy feminists distracts from substantive changes needed to decrease inequalities that disproportionately affect women, migrant populations, and racial and sexual minorities. While this paper focuses on human trafficking and sex work within the United States, the scope of this carceral framework clearly affects lives in similar ways outside our borders (Britton and Dean 2014; Chapkis 2003; Kempadoo 2001).

While others suggest that feminists could embrace a third way by uniting in opposition to sex trafficking while respecting women's agency (Cavalieri 2011), we argue instead that the debate itself is the problem. The oppositional framework shaping this debate is problematic, and the resultant proposals may further harm the "victims" they intend to protect. Current policies, and to a large degree the feminist debates surrounding them, do not make lives more livable or legible. They instead shift our gaze away from the real phenomena constraining choice, pleasure, and survival: systemic and structural inequalities that disproportionately affect LGBTQ persons, poor people, and trans people of color.

Our findings advocate for solutions that address the criminalization of economic migration, sex work, pleasure, poverty, and survival. We extend Sassen's $(2003,258)$ ideas of understanding how the "feminization of survival" operates, who benefits from it, and how we can alter the social institutions and practices that foster justice. We argue that activists and 
scholars need to develop new understandings of contentment that encompass context-specific agency, choice, and survival (Lewis and Marine 2015). Pleasure then becomes less important as a sense of enjoyment or satisfaction and more about the issues of livability and survival—how people survive under strict economic and carceral restraints while maintaining a sense of agency. We also re-envision the idea of danger as a series of threats located within the security state, criminality, and structural inequalities.

\section{Anti-trafficking Movement}

Internationally, the anti-trafficking movement has polarized activists committed to ending the exploitation of women but with very different means to achieve that end. On one side are feminist abolitionists, who believe the root causes of women's exploitation are patriarchies of oppression that reduce women to commodities available for men's entitled purchase. Because gendered life outcomes remain unequal, these feminists understand most forms of sex work as prostitution and exploitation, much as the antipornography feminists see the porn industry as a site of commercialization and degradation. Abolitionist feminists often perceive sex workers as victims of patriarchy and male demand. Queer and transgender individuals are frequently left out of this framework, both as sex workers or clients of sex workers. The antiprostitution "End Demand" movement focuses its attention on prosecuting the consumers of sex work-the clients - and criminalizing the purchase of sex. While many do not advocate penalizing sex workers, this prosecution agenda leaves sex workers little room to navigate the carceral state. Because clients fear arrest, sex workers may be forced to make hasty negotiations in risky, less secure environments. 
In the United States, the anti-trafficking movement has created a strange—but familiarcoalition of feminists, "progressive Democrats, and Republicans who closely identified with the evangelical Christian community" and decry prostitution and women's exploitation (Gulati 2011, 364). Radical feminists and Christian conservatives unite in ending trafficking (primarily sex trafficking) and are now oddly connected to growing anti-immigration sentiment (Shrage 2012; Sassen 2002). Indeed, as Chapkis argues, a slippage occurs when anti-trafficking advocates incorrectly demarcate between trafficked persons and migrants:

The line drawn between the innocent victim and the willful illegal immigrant used to determine punishment and protection is not only a dangerous one, but it is also a distinction that does not hold. Most trafficking victims are also economic migrants. Their victimization most often involves high debts and abusive working conditions, not outright kidnapping and imprisonment. $(2003,931)$

The anti-trafficking movement has been well funded, and, with its focus on policy and prosecution (Tilly and Wood 2012), it has been more successful than other movements in creating an international diffusion of anti-trafficking policies (Britton and Dean 2014). Governments know how to legislate and prosecute; they are less adept at changing attitudes and social structures - the root causes of trafficking and sex work stigma. For example, the Trafficking Victims' Protection Act (TVPA) — the first and prevailing federal-level policy on 
human trafficking - has provisions to prosecute traffickers and protect survivors, but not to prevent trafficking.

Policy goals of protecting survivors through access to safe living spaces, court orders of protection, and visas are imperative, as is prosecuting traffickers and market facilitators who perpetuate coerced labor. Problematically, these efforts only catch people after the crime of trafficking, while the structural factors promoting exploitation remain in place. The violence, abuse, and degradation experienced by trafficked persons are real and substantiated. The approaches taken by most states continue to be reactive, after the abuse has occurred, rather than proactive about the structural factors that lead to trafficking.

\section{Pro-Sex Work Activism}

On the other side of the debate are autonomy feminists who also understand and appreciate the realities of patriarchy and women's oppression, but believe in the right to engage in sex work for reasons ranging from survival to freely chosen legitimate employment. These feminists and allies favor the decriminalization of sex work to ensure sex workers' safety and well-being (Beloso 2012; Cavalieri 2011). By treating sex work as similar to many other forms of service industry employment, they argue decriminalization will decrease abuse, harm, and illegal sex trafficking (Commission for Gender Equality 2014). This perspective, often considered harm reduction, takes a pragmatic approach to commercial sexual exchange.

Pro-sex work activists work to decouple commercial sexual exchange from trafficking and a hierarchy of sexual practices (Weitzer 2012; Hoang 2014). These feminists believe that most sex workers actively choose this employment. When consent to engage in sex as an 
occupation is enacted - even in the many cases where sex work, because it is work, is not fun-it can still be understood as decision-making with agency (Rosen and Venkatesh 2008). Sex workers, much like other freelancers, can cultivate relationships with repeat clients (Ray 2007). This provides stability and increases the potential to refuse relationships with problem clients. As pro-sex work feminists have demonstrated how sex work can be done with agency, critiques of the anti-trafficking movement have also emerged to reconsider the norms of human trafficking research and advocacy (Hoang and Parrenas 2014; Galusca 2012). Multiple scholars have argued that Europe's anti-trafficking movement is a thinly veiled attempt to surveil and maintain national borders (Davydova 2013; Agustin 2007; Bernstein 2007b). The anti-trafficking movement has been tied to the creation of women in the global South as a victim class by inciting fear of their transnational movement and sexualities (Desyllas 2007; Chapkis 2003; Kempadoo 2001; Doezema 2000). Scholarship has noted the similarities between the current anti-trafficking movement and the turn of the century US media panic over "white slavery," which led to a swift political response in the form of immigration restrictions, efforts to prosecute importers and traffickers, and provisions to deport immigrant prostitutes (D'Emilio and Freedman 2012; Spencer and Broad 2012; Donovan 2005; Doezema 2000; Stienstra 1996). A trend of US policy influenced by Protestant religious movements is considered the source of the abolitionist anti-trafficking movement from the 1990s to the present (Shrage 2012; Bernstein 2007a; Soderlund 2005).

Scholars have noted the anti-trafficking movement's creation of an "ideal victim" in need of - and, more importantly, worthy of —rescue (Chapkis 2003; Sassen 2002; Kempadoo 2001). Srikantiah $(2007,187-88)$ describes the iconic victim as gendered female, passive, compliant with traditional modes of justice, and legible as a citizen- “"the iconic victim concept distances 
trafficking victims from the 'illegal alien' stereotype, thus avoiding any association with economic migration.” By portraying all sex workers as victims, some in the antipornography and anti-trafficking movements attempt to claim the moral high ground as they claim to be rescuing women from sex trafficking. The rhetorical distinction between deserving victims of trafficking and undeserving migrants solidifies a union between some anti-trafficking and anti-immigration proponents: “In this way, the Trafficking Victims' Protection Act helps to define 'compassionate conservatism': a willingness to provide assistance and protection for a few by positioning them as exceptions, proving the need for punitive measures against the many" (Chapkis 2003, 930).

\section{The Pleasure/Danger Dichotomy: Creating Unlivable Lives}

The current debates create opposition between human trafficking and sex work and encourage a dichotomy between pleasure and danger. This framework is ideologically restricted to what appears to be mutually exclusive worldviews: sex-positive feminists versus sexsuspicious feminists, constrained agency versus exploitation, labor versus slavery, rights-based policies versus rescue strategies, and so on.

Agentive Feminists

Sex-positive Feminist

Agency within constrained choice

Sensuality

Labor

Rights-based policies

Immigration reformers

Decriminalization

\author{
Abolitionist Feminists \\ Sex-suspicious Feminist \\ Exploitation \\ Commodification of bodies \\ Slavery \\ Rescue strategies \\ Anti-immigration advocates \\ End Demand/Criminalize purchasing \\ sex
}


Global Alliance Against Traffic in Women

Coalition Against Trafficking in
Women

Each side includes thoughtful, committed feminists working to ensure the full enfranchisement and expression of women, LGBTQ communities, and racial minorities - to use Butler's (2004) concept, to ensure the livability of all lives. However, this dichotomous framework does not reflect the lived experiences of our own research participants, who encounter pleasure and danger as interactive, intersecting forces. This narrow, binary approach to creating livable lives distracts from the very real threats that our participants face. We see our projects as offering a path outside of the gridlock of current debates that so frequently call upon these binary structures.

Specifically, we find the ideologies of carceral feminism — what Bernstein calls "a cultural and political formation in which previous generations' justice and liberation struggles are recast in carceral terms" $(2012,236)$ — undergird the pleasure/danger dichotomy, undermine the ways people create livable lives, and have material consequences for our participants. Carceral feminism operates within punitive avenues, a strategic tactic in the US carceral state. It advocates for policy change, which regulates and criminalizes, resulting in fines, arrests, and jail time. Not all policy is carceral; US law has at times been deployed to uphold sex workers rights (Karalekas 2014). Policy may be used to promote autonomy and contentment, as in the case of antirape and pro-choice legislation, or sex negativity, as was the case of antiporn legislation. Policy can also reinforce normative ideologies about pleasure and danger and how those forces expand or contract the options for a livable life. As Butler writes, "What is most important is to cease legislating for all lives what is livable only for some, and similarly, to refrain from proscribing for all lives what is only unlivable for some" $(2004,8)$. When policy upholds one 
half of the pleasure/danger binary—or conflates sex work with sex trafficking—some lives become unlivable, unrecognizable within its frames.

For all our participants, trafficking, exploitation, and abuse are egregious violations. But current anti-trafficking legislation applied within the carceral state fails to address the complex issues of sex work and human trafficking at great and unnecessary cost to our participants, operating with only one perception of how livable lives can flourish. Policy changes intended to produce humanitarian results - for example, the TVPA's protections for trafficking survivorsactually resulted in arrests or the denial of benefits under the basis of failing to prove one's victimization (Chapkis 2003). Using Butler's terms, we can reread the TVPA to show how those who could not prove their trafficking had "no norms of recognition" within the legislation and, thus, became "foreclosed from possibility" as a survivor, as a livable life $(2004,31)$. This is not to say that all anti-trafficking policies are inherently wrong. Rather, solutions to gender-based inequality and violence that perpetuate a prison industrial complex, which target certain populations — populations already oppressed by racism, sexism, and classism — for increased force and violence are the problem (Lawston and Meiners 2014).

The influence of the carceral state is evident in anti-trafficking policy. The numbers of human traffickers prosecuted within the framework of the TVPA reflect the disproportionate numbers of incarcerated young African American and Latino men nationally. Out of the 488 total trafficking suspects identified between 2008 and 2010, almost half were African American, and nearly one-fourth were Hispanic/Latino (US Department of Justice 2011). As police efforts to combat human trafficking increasingly focus on people of color as perpetrators, all persons engaged in street-level sex work—pimps, clients, and sex workers—and nonconsensual sex 
trafficking find themselves increasingly subject to the surveillance and punition of the carceral state (Bernstein 2012).

\section{Interdisciplinary Conversations}

Our thinking on the current inadequacy of the pleasure/danger binary comes from an interdisciplinary conversation at the nexus of two ongoing but completely independent research projects: Kennedy’s national research with sex workers and Schwarz and Britton's work studying the Midwest anti-trafficking movement. One would think based on the starting points of each of our projects (sex work versus trafficking) our findings would be mutually unintelligible, either fraught by inherent differences or reinscribing current sex war ideologies. Rather, our shared commitment to fostering conversations across departments, fostered by our membership in IPSR, gave us a platform to understand each other's work outside of this contentious divide. We began to think past our own narrowly focused research projects to larger normative understandings of criminality, risk, resilience, and agency that impact marginalized populations. It became clear that our findings - based in the actual experiences and voices of sex workers, trafficking survivors, and service providers- had more in common than any of us expected, though definitively not in the frequently circulated argument that all sex workers are trafficked. Participants were concerned with finding different paths toward livability and survival.

Kennedy's research began on the Internet, which has been identified as a key site of communication for nonnormative practice, to observe over one hundred self-identified sex work bloggers, then progressed to interviews with sex workers. She researches how the Internet affects the sex industry and sex work stigma. Kennedy is a sociologist and feminist. Her theoretical 
stance held that, while there is undoubtedly a hierarchical valuing of sex work in society-i.e., normatively stripping is somewhat acceptable, while street prostitution is intolerable-from the vantage point of many of the workers, this hierarchy is a useless social construction. A hierarchical valuing of sex work disadvantages sex workers who have worked in more than one sex work trade (a regular practice in this workforce), it justifies worse treatment of some sex workers relative to others, and it divides the workers, further discouraging their attempts at activism beyond the disadvantage currently resulting from arrests, incarceration, social isolation, and widespread sex work stigma. Observing sex workers on the Internet, she found many expressly criticize the sex work hierarchy, which some label the whoriarchy or the ho-iarchy. For this reason, she defines sex work as the commercial exchange of sex or sexual provocation for money, an umbrella definition that includes fourteen different kinds of work.

Kennedy began collecting interviews in 2013. She posted a Call for Participants (CFP) where she had been observing sex work bloggers, and she has to date conducted thirty-six indepth interviews with people who answered the call or were referred to the project. The interviewees ranged in birth year from 1972 to 1994 . Thirty-five of thirty-six were women including one trans woman. Twenty-eight interviewees self-identified their race/ethnicity status as white, one as Native American, two as Black, two as Asian American, and three as mixed (Asian Indian, Half-white/Half-Iranian, and Latina/white). Twelve identified their sexual orientation as bisexual, nine as queer, six as pansexual, two as heterosexual, one each as asexual, bicurious, heteroflexible, lesbian, omnisexual, straightish, and one said it depended on the day. The interviewees had worked or were currently working in the sex industry in thirty-three of the United States, plus Ontario, Canada, and Australia. Aggregating their responses, the following sex work trades are represented: cam play for pay, escorting, erotic writing, fetish modeling, 
nude dancing, nude modeling, phone sex service, pornographic acting, power play for pay, sensual massage, stripping, and sugaring.

Britton and Schwarz are gender studies scholars who approach human trafficking research from a human rights position of ending gender-based violence and finding upstream, structural solutions to vulnerability, exploitation, and trafficking. They have been lead researchers in an ongoing two-year project located across Kansas and Missouri to discern the sites of vulnerability to human trafficking, including both sex and labor exploitation. They have sought to map physical sites of vulnerability (truck stops along the major highways that bisect the country and the city; massage parlors; sporting and conference venues; military bases; agricultural and construction sectors populated by migrant labor), as well as locate moments within the life course that could create vulnerability (aging out of the foster care system, moments of child abuse and trauma, periods of homelessness, moments of income/healthcare insecurity).

To date, Britton's research team has conducted fifty-four intensive interviews with service providers in the Midwest. Utilizing a semistructured interview protocol, the researchers interviewed community stakeholders working for a variety of organizations that encounter vulnerable, exploited, or trafficked persons. These interviews range from thirty minutes to one hour, yielding rich narratives of vulnerability, agency, risk, and resilience. The research team has used both inductive and deductive analysis with ATLAS.ti software to understand how trafficking occurs as well as points of intervention to reduce vulnerability before exploitation occurs.

While we worked to understand and identify individual risk factors (such as homophobia, transphobia, cognitive and learning disabilities, undocumented status), we uncovered even more 
significant structural risk factors: poverty, homelessness, incarceration, and deportation.

Similarly, these interview narratives demonstrate a nuanced picture of vulnerable populations' agency and resilience, including looking to their families and children as reasons to survive; having a belief in education as a pathway out of trafficking; and enduring violence and exploitation as a means to create a better future for their families and children. These become moments of agency that they use to survive and thrive.

While each project is shaped by our separate research agendas, all three researchers define themselves as feminist empiricists. We base our findings and our policy prescriptions on empirical work that is guided and framed by our participants' lived experiences.

\section{Findings}

The interdisciplinary conversations occurring above and based on our very different research projects led us to some new normative understandings of risk, resilience, pleasure, survival, and danger. We argue the pleasure/danger binary distracts from the larger threats we are not tackling. Specifically, allowing the carceral, security state to define the argument, design the solutions and policies, and codify and criminalize pleasure perpetuates the gridlock that prevents structural changes that eliminate harm, which is the goal of both agentive and abolitionist feminists.

Our participants showed how the factors that compel someone into trafficking or coercive transactional sex are part of a constrained choice: many vulnerable or trafficked persons have some degree of agency that facilitated their engagement in certain forms of labor, even if that labor was coerced. Multiple push factors result from "situations of economic, political, religious, and military instability or tension" compounded by poverty (Srikantiah 2007, 163). These factors 
can be "atmospheric" or individual—for example, a person living in a stable environment might feel compelled to leave that environment because of "strained family circumstances," placing them in a similar position of vulnerability to someone leaving a war-torn country or living in poverty (Srikantiah 2007, 192). Acknowledging constrained choice-making reveals the complexity of agency within systems of trafficking (Weitzer 2014; Cavalieri 2011; Chapkis 2003; Sassen 2002).

The term "coercion" here is still problematic. Anti-trafficking scholars have shown how laborers were arguably coerced into certain exploitative practices through their relative poverty, family pressure, or the general lack of options. What might read as coercion to the antitrafficking movement reads to the laborers as exercising their constrained agency; these people would be failed by a definition of trafficking specifically rooted in "coercion." Similarly, the line between an exploited trafficking victim and an exploited undocumented worker who chose to be smuggled into a country is narrow (Cavalieri 2011; Chapkis 2003; Sassen 2002). Denying exploited laborers state protection or threatening them with deportation because they were initially "culpable" in their migration contradicts the human rights goals of anti-trafficking efforts. Consent is no longer relevant in exploitation.

In place of a pleasure/danger binary, we envision pleasure and danger in new ways. Pleasure becomes a dynamic form encompassing both pleasure as autonomy and sensuality (such as joy in one's work) and pleasure as agency within a constrained environment (such as the ability to feed your family). Dynamic pleasure and contentment, as described in our data below, are worthy of feminist advocacy (Reger 2014). This has meaning especially in societies and systems that seek to deny livability through incarceration, deportation, violence, and so on. Danger, on the other hand, becomes the intertwined structural and individual-level risk factors 
that created material harm: the threat of incarceration or deportation, neoliberal economic policies that defund the welfare state, anti-LGBTQ policies that facilitate discrimination, and the privatization and defunding of key social services. A person's individual identities can also compound real danger of discrimination or vulnerability: race, citizenship status, poverty, LGBTQ identity, disability, homelessness, income insecurity, and health crises.

Figure 1: The Pleasure Bubble

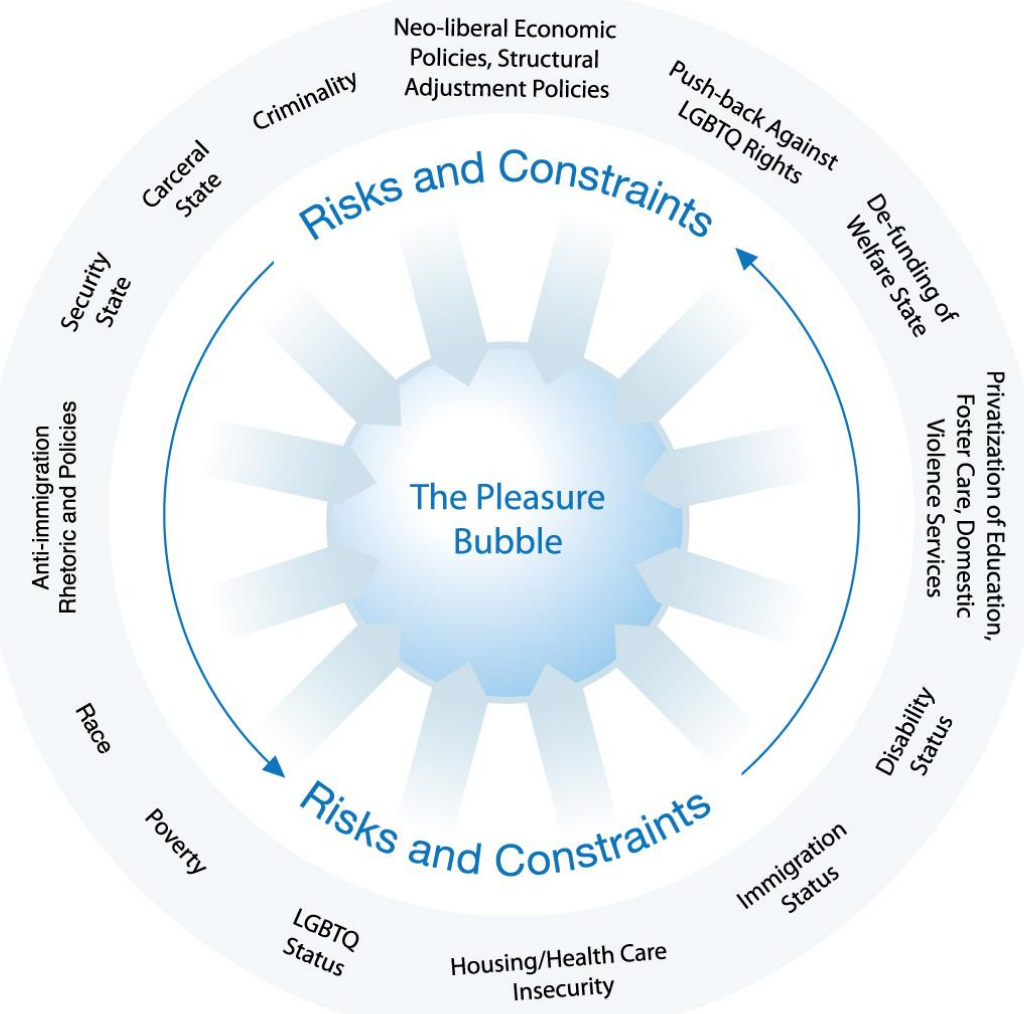

We provide the above diagram to illustrate this alternative way of thinking about structural injustice, sex work, and sex trafficking. Both top-down forces and individual/identity factors 
intertwine to constrain pleasure, agency, and survival. Pleasure is affected, but it is not crushed or absent. Within our separate empirical projects, we continue to hear from people redefining pleasure, danger, choice, and autonomy. Below, we present several examples our participants shared with us that demonstrate their material realities, constraints, and moments of agency and pleasure. Interviewee pseudonyms are used to maintain confidentiality. We also refer to our interviewees in the terms they used to describe themselves or, in the case of service providers, their clients. We know these terms are slippery and that people may choose to self-identify differently across place and time. Our use of these terms is not meant to conflate sex work and human trafficking but rather to respect the complex ways individuals define themselves, their work, and their identities.

\section{Structural Factors Contributing to Sex Work and Human Trafficking}

Our participants had various constraints, risk factors, or identities that affected their ability to make choices, experience pleasure, and have a livable life (Butler 2004). Britton and Schwarz found that the vast majority of the persons vulnerable to trafficking in their study faced poverty, unemployment, and income insecurity. Both domestic and foreign-born survivors faced an economic precarity that compelled them to take risks at work, to pursue work that was abusive, or to "consent" to work that eventually led to their trafficking. This economic insecurity often also translated into housing and health care insecurity. A lack of affordable healthcare and insurance were push factors for trafficking.

Each of these factors - poverty, housing insecurity, and a lack of affordable health care/insurance — was dramatically compounded for undocumented workers. Undocumented 
persons can have a fear of arrest and deportation that prevents them from seeking assistance.

These vulnerabilities are exacerbated by limited English-language skills that prevent them from understanding their possible protection under trafficking laws.

Similarly, individuals_ especially youth—who identified as LGBTQ faced familial rejection, social isolation, or harassment that drove many into homelessness and to engage in survival sex. These youth may become targets of trafficking predators who offer protection. There is extensive documentation of the linkage of LGBTQ youth and homelessness (FergusonColvin and Maccio 2012; Gordon and Hunter 2013), and trafficking scholars are beginning to document the vulnerability LGBTQ persons face to survival sex and trafficking (Dank et al. 2015). These vulnerabilities often continue into adulthood.

Schwarz and Britton found another pattern: individuals who had emotional, cognitive, or learning disabilities may be targeted by trafficking predators. Traffickers sought youth whose disability status isolated them, made them feel inferior or different, resulted in bullying, or enticed them into unhealthy relationships. While no one asserted that disabled persons need special protection, participants did indicate that there were "windows of missed opportunity" to identify these vulnerabilities, for example, interventions with case managers or social workers that failed to see exploitation or trafficking at play. Most of the sex-trafficking survivors in the study also had experienced some form of child abuse-sexual, emotional or physical. More resources in schools, foster care systems, and community social services would enable social workers to assist all these youth through such vulnerability.

Given the international economic downturn in the last two decades, our anti-trafficking participants indicated that the neoliberal economic policies constrained the choices of their clients. Sheila, a victim advocate at a domestic violence shelter, indicated she has seen the 
impact of the defunding of government programs for health care, childcare subsidies, and mental health programs in the lives of her clients:

Right now, it feels like we are just looking backwards, especially because right now, because of the economic crisis, we are looking for someone to blame. We are punishing the most vulnerable. ... There was a remark made [by a state legislator], we will cut what we need to, diminish their, not only their food stamps, but let's diminish their daycare subsidies, so just work more. Well, what world do you live in? Not too long after that, there was a program on PBS about the enormous percent of people's income that goes to daycare. So if you're on a minimum job, it all goes to daycare. ... And then we have gun shootings and blaming mental health. So we need to up the mental health and right next to that we are doing budgets, so what do we cut? Medicaid, for people who cannot afford healthcare or mental healthcare. Like I said, to me it seems like we are sliding backwards in terms of victim blaming. ${ }^{1}$

This precarity is also seen in the material realities of sex workers who are working to find other avenues of employments. In order to understand the ongoing sex-work stigma, Kennedy asked her participants whether they had experienced harassment, or exclusion from jobs, education, or social services, due to their participation in the work: 
Exclusion from jobs: yes. I was actually for a year or two, a year or two ago I was actively looking for another job, and I think it was solely based on my employment gap, and the fact that I said I was an independent contractor. I think yeah, nobody even called me back, and I'm extremely qualified for all the jobs I applied for. But it could also have been the, you know economy or job market, it could have been that. It could have been a lot of things, but exclusion from jobsmaybe. $^{2}$

Similarly, there are problems in trying to address vulnerability through legislation, which creates guidelines and scales and frameworks that do not match lived experiences. As Carol states, she sees that many sex workers are driven by economic constraints and material poverty:

When they [the police] do their prostitution stings, they think they are really out there combating trafficking. They are getting a few tricks, they are getting their hands smacked, but they are not getting humiliated in court like the women. . . You get these local girls who are just trying to survive, maybe they don't have a big pimp daddy, they just put themselves on Backpage or Craigslist or whatever, she is just out there trying to get some money to pay for her kids school shoes or whatever, she gets caught up in this mess. She doesn't have $\$ 1000$ to pay for a fine. She doesn't have that. So how is she going to get it? If she is having to 
prostitute to buy her kids school shoes, she is probably going to go out and prostitute to pay her fine. ${ }^{3}$

Here, Carol outlines how attempts to rescue trafficking victims led to the further impoverishment of sex workers, who were already vulnerable to structural poverty and now had to pay fines for their arrest. Rather than dealing with the factors causing poverty, punishing sex workers may drive them into more exploitative situations.

\section{Constrained Pleasure}

Many of the participants in our two projects talked about pleasure in a range of forms- from experiencing sensuality, to having agency, to earning money on their terms, to surviving discrimination and alienation from families or communities. As we discussed the findings of our two studies, we began to conceive of pleasure not as a continuum, with opposed poles, but rather as a fluid, elastic form. Sex workers we spoke with described their occupations as often occurring in environments of their choice characterized by safety, control, and autonomy. They described worker/client exchanges of different but equal power. The exchanges were often mutually trusting, respectful, and communicative.

We argue one way to think about pleasure is the ability to express agency within a constrained environment. Service providers combating trafficking often worked to encourage their clients' agency, including the ability to state their own needs: 
Everybody is at a different space, so we do not have a set program. We determine in partnership with that person what they need. We let them tell us about their lives. We don't tell them, because they are the experts on their lives, even if they are crazy out of their minds. They are the experts on their lives, we are not, you know. They don't always know what is best for them . . . but they know what they want, they know what they need, and most of what we try to do, step one is building a trust relationship. ${ }^{4}$

In order to avoid retraumatizing trafficked persons coming from a position of constrained agency, Carol emphasized the collaboration between herself and her clients. There is no programmatic path from vulnerability to rehabilitation; rather, she uses a "survivor-first" model, allowing people to opt in and out of services and resources as needed while fostering their resilience during times of self-sufficiency (Schwarz and Britton 2015). These formerly trafficked persons experience pleasure by cultivating expertise and authority over their own rehabilitative processes, leading to an individually satisfying experience. Within Carol's organization, she does not require proof of fraud, force, or coercion (as would be required under the TVPA if she were a government agency), but instead grants her clients the ability to present their own experiences as worthy of whatever interventions each individual deems necessary, restorative, and critical to their own understandings of livability.

If your environment is heavily surveilled or very vulnerable, pleasure may be constricted, but it never fully disappears. Even the ability to survive has value and meaning. We are not in 
any way arguing that coercion, force, or fraud are pleasurable. We are saying that multiple effects can be experienced at one time: the achievement of survival at the same time as the crush of trafficking. For the sex worker, this was evident, for example, at a sensual massage facility where a sex worker spoke of enjoying camaraderie with coworkers, at the same time as the pain of stigma from doing a job that is judged as suspicious or immoral. The types and forms of agency and autonomy are obviously very different in situations of extreme exploitation. The very act of survival demonstrates agency. Alternatively, if someone exists in an environment with more social control, mobility, and autonomy, pleasure can be expansive, inviting exploration of new social norms and ideas.

Holly, a staffer at a sexual violence advocacy organization, echoed an emphasis on clientcentered approaches. She stated,

You know we're not going to ask them to tell us all the details of what happened or why they're here so it's very much up to them what they want to disclose and what they don't. . . . Often times they talk about their boyfriend or something like that or feeling like that person has to get $[$ sic $]$ their permission in order to do certain things. So we might hear someone say as we're trying to set up follow up medical care that I don't know if I can do that, my boyfriend doesn't like them going to the doctor without him or something like that. So just hearing things like that can sometimes spur red flag, just an indication that a person does not have a lot of control over their own decision making, over their behaviors. ${ }^{5}$ 
In this quote, the client's ability to exercise her own bodily autonomy is trumped by the boyfriend's pleasure — what he would like, where he would grant permission. Holly's work is not to dictate what steps her clients should take within the range of services offered-medical, therapeutic, legal—nor to push clients to disclose beyond their comfort levels, but rather to facilitate spaces for her clients to choose among these services or to opt out entirely, if they so desire.

Sex workers of all types of employment expressed a range of pleasure-from pleasure in the enjoyment of their work to pleasure in making a living. As Grace, a stripper, told Kennedy,

I started when I was 21, and I started at a prominent club in Portland. From high school I always told all my friends, if I ever have the body I'm gonna do it. I don't really know for what reason other than I can. I started up, and I've been doing it ever since, and now I work at another prominent club in Portland. I love it. I love my job. It was just part of my plan to take care of myself. I see it as a very independent type of job. I felt and I still feel that, while it is objectifying and I'm playing into social stereotypes and gender roles and all that, I still feel like I would be kinda silly not to take advantage of the type of money you can earn while basically doing nothing (laughter). ${ }^{6}$

While acknowledging that she works within a constrained environment — one she describes as objectifying and fulfilling particular gender roles - Grace has found that the independence and 
pleasure in her job is a driving force in her desire to stay in the industry. The ability to make money "while basically doing nothing" (though flirting and dancing for six hours in 5-inch heels is not nothing) is a source of real pleasure and power for her.

Britney, a transgender escort interviewed by Kennedy, spoke about having not only pleasure in her job as an escort but also autonomy:

And a lot of [the escorts who advised me] I confess were confused, the ones who were helpful to me were confused because they came from a background where they were turned out, they were turned out by a friend when they were in dire straits, and I was coming into it with a position of "if I really hate this, I don't have to do it, but I want to have the experience at least once. And see how I feel about it, because it could be a thing." And I loved it, I did. It was really intensely meaningful to me on a variety of different axes. And I still miss it. Even though obviously, you know, I ran into a lot of bullshit. But I do miss it. ${ }^{7}$

Britney was mentored by others in the industry who had been driven to escorting through isolation/vulnerability. Britney had much more agency and authority in her work. It was her choice to become an escort, and escorting was something she could choose to continue or stop. She describes the pleasure of fellowship with mentors as well as with the actual work. Sex work had not just agency, but great meaning for Britney. 
Marilyn, another escort interviewed by Kennedy, discussed the possibility of exploring other types of sex work in a different kind of world — one framed not by danger, but by a feminism with space for women to explore sexuality without violence, objectification, and exploitation:

I've played with the idea of doing porn, but I guess it's my nature to be a little more planned out and to really reflect on whether I want to do it or not and not make sudden moves when it comes to that kind of thing especially with the fact that it's recorded and will always exist. There's no getting away from it once I do it. But I really, that Feminist Porn Conference opened things up for me. Because I really felt like this was a movement, and this is, you know, steaming along. This is about women choosing to be sexual and wanting the freedom to be sexual, without being raped, without being judged and hated, while also being lusted for. ${ }^{8}$

Marilyn was exploring the possibility that a new form of pleasure, driven by free choice and within a feminist framework, could be created. Her experience of pleasure stemmed from being involved with a pro-sex work social movement and the belief that she was contributing to social change, a change that empowered women to make their own decisions regarding their bodies, employment, and what constitutes pleasure.

The range of pleasure also encompasses having a sense of a "typical" day where one is relaxed, in charge of her schedule, and having fun, as Rebecca, a Pro-Domme, described: 
A typical day, I guess this past Thursday was pretty typical. I saw three clients; I had four scheduled. I slept in until like 9:00, had breakfast, went to the studio, saw my first client at 11:30. Had a nice session. I don't even remember what we did. It wasn't memorable. I mean typically my clients just come in and let me do whatever I want to, which is awesome. It just, it kinda depends on my mood. I'll typically do you know some flogging, or I'll use crops or canes, definitely pinwheels. I love like tickle torture, getting that response from clients. Do some violet wand play. I do a little bit of body worship, like if they're into feet: that's great I'm like "Yes please, massage my feet."

Rebecca, in charge of her schedule and what occurs in her sessions, experiences pleasure on a variety of levels - the cognitive experience of top space, the sensory experience of a foot massage, and the ability to live life and experience fulfillment on her own terms.

\section{Critique of Carcerality and Structural Violence}

Perhaps the most common thread between our projects was the danger our participants felt from the carceral state and from their own structural vulnerability. Whether someone was talking about a trafficking survivor who feared deportation or discussing the multitude of laws they broke to engage in commercial sex, there was a strong fear of incarceration and deportation. 
Even when crimes are committed during the course of being trafficked, many US states still limit—or do not have—vacatur statutes to expunge prior offenses. We were struck by how the danger of incarceration was linked in a vicious cycle with other structural risk factors, like poverty, homelessness, unemployment, and occupational criminalization. These risks intertwined with the danger of incarceration, such that being in poverty and identifying as a person of color is linked to a risk of criminalization. As Carol argued, prior arrests and prosecutions limit the ability for survivors to create new lives and new opportunities:

Most of our people have been arrested numerous times, a lot of them are carrying drug felonies, which is really too bad here . . . because, if you are a drug felon here, you cannot get food stamps. . . . So that leads to more crime, because when you cannot feed yourself and you're hungry, what are you going to do? You're going to go out to prostitute to get some money so you can eat or get a trick to feed you or find a pimp that will maybe feed you once a day or something. . . . So it's just this really poverty cycle that these folks get into, and because these are the really challenged people, they just kind of tend to stay stuck down in this poverty mire. ${ }^{10}$

While many argue that anti-trafficking and abolitionist feminists exclusively support carceral approaches, our empirical findings are more nuanced. As Carol indicates, some service providers hold more complex relationships toward the carceral state and acknowledge the violence it can 
perpetuate against their clients. Criminalized approaches to sex work and human trafficking run the risk of contributing to increased vulnerability. A precarity continuously reoccurs within poverty, risk, and exploitation when someone is operating in a carceral framework rather than a human rights framework. The carceral state "involves disciplinary mechanisms that operate to lock people's current and future life choices and possibilities into unequal and unfree capitalist social relations and to limit their social and physical mobility within these relations" (LeBaron and Roberts 2010, 20). Life is reduced to either imprisonment or possible future arrest.

Based on their prior involvement in the carceral state-involvement that is permanently marked a felony designation - these trafficking survivors remain locked into a system that denies them social benefits and limits their abilities to access basic goods. This restriction creates an environment where survivors of trafficking must return to those spaces of trauma and violence in order to escape the cycles of poverty, therein exchanging long-term exploitation for short-term survival.

Sex workers also navigate risk by continuously recalculating what they will and will not do with clients, under fear of arrest and fines:

I do strap-on play, and that . . . so strap-on play, golden showers, and urethral sounding are three types of activities that I'm more cautious with because they're clearly illegal. And I mean all of it is technically illegal, but you know if a cop comes in and is like " $\mathrm{F}^{* *} \mathrm{k}$ me in the ass for cash" and I agree to it, obviously I'm going to get arrested. So I tend to not do those behaviors with first-time clients and wait until I get to know them a little more and make sure they're safe, before 
going into those types of activities. ${ }^{11}$

The stigma of sex work often positions workers in deep social isolation. Arrests and financial penalties could drive them into vulnerable, precarious, or even exploitative situations where they may lose agency or autonomy.

Carol talked in great detail about the arbitrary division between anti-trafficking law and prostitution law, specifically in terms of who receives protection and who becomes criminalized:

And it really gets me that one day you can be seventeen years old, and you're caught up in prostitution and get picked up by law enforcement or some other authority, maybe you're skipping school or whatever, you are going to be automatically considered a victim because you are under the age of eighteen. You don't have to prove force, fraud or coercion because you are a minor, so that always falls into that category. But let's say you have your birthday the next day, and now you are eighteen, and you get caught up in a sting or whatever with law enforcement, now you are prosecuted for prostitution. You're not considered a trafficking victim anymore, even though nothing in your life is different. ${ }^{12}$

Here we see the limitations of a carceral approach to trafficking and prostitution. Law enforcement wants clear guidelines to implement. But the line between 17 and 18 years of age can be as brief as 24-hours long. Structural factors that coerce someone into commercial sex do 
not disappear overnight, but someone can shift from being a protected victim to a criminal overnight within this framework.

\section{Conclusion}

Our research reveals that sex workers and human trafficking survivors in the United States operate within a space constrained by various types of restrictions, including economic and identity constraints. Sex workers and trafficked persons are negatively affected by carceral interpretations of state power: anti-immigration policies, the security state, the prison system, neoliberal economic policies, and the defunded welfare state. Individuals also had a deepening of these constraints based on their personal economic insecurity or identity factors such as a disability or LGBTQ status.

While it may seem that the dangers of the carceral state and structures like poverty are unrelated, we find they are interwoven so closely as to be mutually reinforcing. By approaching trafficking and sex work within a carceral framework, people's imperfect but working solutions to poverty, mental illness, and challenging parental responsibilities may become interpreted as crimes; the pursuit of criminals in turn creates and may drive poverty. The climate is such that almost all sex workers Kennedy interviewed harbored some fear they would get in trouble with the police during the course of their work. Similarly, a key theme encountered by Britton and Schwarz in their interviews was the fear that labor and sex trafficking victims had of arrest or deportation. Rather than addressing poverty, the state increases funding of the security infrastructure at the cost of vital health care, housing subsidies, and poverty alleviation 
programs - programs that could by and large limit the number of people who are vulnerable to trafficking.

Compressed within these two sets of forces we find new ways to envision how to create livable lives: as the drive to establish autonomy, to identify one's own agency, to persist and live, and even to engage in rebellion against unjust policies. We interviewed people working within deeply constrained environments who were crafting ways to survive. We encountered people who were reacting against the hegemonic rhetoric of stigma and pushing back against the myth of an "ideal victim."

We argue there is no singular solution for the "danger" we have identified. Education funding, housing programs, employment programs, and health care access all represent upstream solutions that prevent exploitation and trafficking before they occur. Our policy recommendations include stronger rights-based education and English-language instruction for international migrants; reinvesting in education, housing, jobs training, and poverty alleviation programs; increasing the number of social workers and available funding for abused and neglected children, foster care programs, and disabled youth; the decriminalization of sex work; and strengthening state and local policies to support LGBTQ rights. Prosecutions, incarcerations, and the security infrastructure are reactive measures that have proven expensive and ineffective as deterrents - and they also are implemented after someone has been harmed, often resulting in causing further harm to those who are most vulnerable. Alleviating poverty gives individuals the agency to pursue education, work, and family on their own terms and without fear of exploitation or arrest.

Attempts to decriminalize migration and sex work are important policy debates to be examined apart from moralistic and sex-negative ideologies, and progress has been made in these 
types of discussions. For example, the human rights organization Amnesty International undertook a full-scale review of the research and has recommended decriminalization (amnesty.org 2015). While a full discussion of the decriminalization of sex work is outside the scope of this paper, there is a growing body of scholarship disputing the success of criminalizing the purchase of sex (the End Demand model) and arguing that decriminalization may make identification of exploitative sex work easier to identify (Weitzer 2012). Similarly, antiimmigration policies — even some anti-trafficking policies — may be driving more immigrants underground, exposing them to harsher exploitation and heftier transportation fees that make them vulnerable to violence and exploitation (Chapkis 2003; Sassen 2002). Approaching all of these problems with criminalization and prosecution misses the opportunity for economic reform that addresses these vulnerabilities before exploitation occurs. We also should examine new ways to understand pleasure as a means to craft a livable life—one of exercising autonomy, finding ways to survive, and creating lives free from violence and exploitation.

\section{Acknowledgements}

Initial funding for the ASHTI project was provided by a Level II Strategic Initiative Grant from the University of Kansas. We would like to thank the Institute for Policy \& Social Research at the University of Kansas for their ongoing support of the ASHTI project, including funding, data management, and project facilitation. We also thank the Department of Political Science at the University of Kansas for their ongoing support of this project's student assistants. We would like to thank the entire ASHTI faculty working group for developing the theoretical foundations and research base for this project. In particular, we wish to acknowledge Dorothy Daley, Emily 
Rauscher, Megha Ramaswamy, Katie Cronin, Akiko Takeyama, Mariya Omelicheva, Shannon O’Lear, Travis Weller, Steven Maynard-Moody, Xan Wedel, Kate Lorenz, and Larry Hoyle. Additionally, we must thank graduate research team for their work conducting interviews with service providers: Ranya Ahmed, Danny Alvord, Sammy Badran, Alex Cloyd, Carolina Costa Candal, Ryan Daugherty, Jennifer Chappell Deckert, Rachel Denney, Luke Herrington, Chris Higginbotham, Anna Karpusheva, Josephine Kipgen, Ryan Louis, Najmeh Moradiyan Rizi, Marcy Quiason, Sierra Reicheneker, Aminata Seck, Brian Turnbull, Sherry Warren, Marcus Williamson, and Andrew Zarda. A special thanks to our undergraduate research assistants, Azmain Ashraf, Nick Ball, Madeline Caywood, Jyleesa Hampton, and Allison Williams. We thank the sex workers throughout the United States who generously gave of their time to speak with Kennedy, and those who blog about their work to promote understanding and combat injustice. Finally, we want to thank the service providers whose interviews provided such rich insights into the cycles of vulnerability, exploitation, and trafficking that exist in Kansas City and neighboring communities.

Corinne Schwarz is a PhD Candidate in the Department of Women, Gender, and Sexuality Studies at the University of Kansas. Her dissertation research looks at the intersections of streetlevel bureaucracy and anti-trafficking work. Schwarz has conducted fieldwork in the Midwest to understand how street-level workers encounter human trafficking in their communities and organizations. She also serves as a Graduate Research Assistant for the Anti-Slavery and Human Trafficking Initiative (ASHTI) at KU.

Emily J. Kennedy researches topics in sociology, organizations, technology, and the law. She 
collected and analyzed data on Web-use and Internet effects on legal and illegal commercial sex practices in the United States. Kennedy specializes in correctional facility program evaluation, the formation of criminal identities, and stigma.

Hannah Britton is an associate professor in the departments of political science and women, gender, and sexuality studies. Britton's scholarship focuses on gender and African politics, gender-based violence, human trafficking, and qualitative research methods. Britton is also the Director of the Center for the Study of Injustice at the Institute of Policy \& Social Research at the University of Kansas. In this role, she coordinates KU's Anti-Slavery and Human Trafficking Initiative (ASHTI), which is a working group of faculty and students engaged in teaching and research about slavery, labor exploitation, and commercial sexual exploitation. ${ }^{13}$

\section{Notes} transcript.

1. Sheila (domestic violence shelter), interview by Corinne Schwarz, November 14, 2013,

2. Grace (stripper), interview by Emily J. Kennedy, March 6, 2014, transcript.

3. Carol (anti-trafficking outreach organization), interviewed by Corinne Schwarz, October 15, 2013, transcript.

4. Carol (anti-trafficking outreach organization), interviewed by Corinne Schwarz, October 15, 2013, transcript.

5. Holly (sexual violence advocacy organization), interview by Corinne Schwarz, October 21, 2013, transcript.

6. Grace (stripper), interview by Emily J. Kennedy, March 6, 2014, transcript.

7. Britney (escort), interview by Emily J. Kennedy, February 28, 2014, transcript.

8. Marilyn (escort), interview by Emily J. Kennedy, June 26, 2014, transcript.

9. Rebecca (pro-domme), interview by Emily J. Kennedy, November 14, 2014, transcript.

10. Carol (anti-trafficking outreach organization), interviewed by Corinne Schwarz, October 15, 2013, transcript. transcript.

11. Rebecca (pro-domme), interview by Emily J. Kennedy, November 14, 2014,

12. Carol (anti-trafficking outreach organization), interviewed by Corinne Schwarz, October 15, 2013, transcript. 
13. All authors contributed equally, and we are listing the names in reverse alphabetical order.

\section{References}

Agustin, Laura Maria. 2007. Sex at the Margins: Migration, Labour Markets and the Rescue Industry. London, UK: Zed Books.

amnesty.org. 2015. “Global Movement Votes to Adopt Policy to Protect Human Rights of Sex Workers.” Amnesty International, last modified August 11, 2015. https://www.amnesty.org/en/latest/news/2015/08/global-movement-votes-to-adoptpolicy-to-protect-human-rights-of-sex-workers/.

Beloso, Brooke M. 2012. "Sex, Work, and the Feminist Erasure of Class.” Signs 38 (1): 47-70. Bernstein, Elizabeth. 2007a. "The Sexual Politics of the 'New Abolitionism."” Differences: A Journal of Feminist Cultural Studies 18 (3): 128-51.

2007b. Temporarily Yours: Intimacy, Authenticity, and the Commerce of Sex. Chicago: University of Chicago Press.

—. 2012. “Carceral Politics as Gender Justice? The ‘Traffic in Women' and Neoliberal Circuits of Crime, Sex, and Rights." Theory and Society 41 (3): 233-59.

Britton, Hannah, and Laura Dean. 2014. "Policy Responses to Human Trafficking in Southern Africa: Domesticating International Norms.” Human Rights Review 15 (3): 305-28. Bureau of Justice. 2012. Arrests in the United States, 1980-2012. Washington, DC.

Butler, Judith. 2004. Undoing Gender. New York: Routledge. Cavalieri, Shelley. 2011. "Between Victim and Agent: A Third-Way Feminist Account of Trafficking for Sex Work.” Indiana Law Journal 86: 1409-58. 
Chapkis, Wendy. 2003. “Trafficking, Migration, and the Law: Protecting Innocents, Punishing Immigrants." Gender and Society 17 (6): 923-37.

Commission for Gender Equality (CGE). 2014. "Decriminalising Sex Work in South Africa." Braamfontein, South Africa. http://www.cge.org.za/wp-content/uploads/2014/05/CEGDecr.pdf.

Dank, Meredith, Jennifer Yahner, Kuniko Madden, Isela Banuelos, Lilly Yu, Andrea Ritchie, Mitchylle Mora, and Brendan Conner. 2015. "Surviving the Streets of New York: Experiences of LGBTQ Youth, YMSM, and YWSW Engaged in Survival Sex.” New York: Urban Institute.

http://www.urban.org/sites/default/files/publication/42186/2000119-Surviving-theStreets-of-New-York.pdf.

Davydova, Darja. 2013. “Criminal Networks, Unfortunate Circumstances, or Migratory Projects? Researching Sex Trafficking from Eastern Europe.” Cultural Dynamics 25 (2): 229-43. D’Emilio, John, and Estelle Freedman. 2012. Intimate Matters: A History of Sexuality in America. 3rd ed. Chicago: University of Chicago Press.

Desyllas, Moshoula Capous. 2007. “A Critique of the Global Trafficking Discourse and US Policy." Journal of Sociology \& Social Welfare 34 (4): 57-80.

Doezema, Jo. 2000. 'Loose Women or Lost Women? The Re-Emergence of the Myth of White Slavery in Contemporary Discourses of Trafficking in Women.” Gender Issues 18 (1): $23-50$.

Donovan, Brian. 2005. White Slave Crusades: Race, Gender, and Anti-Vice Activism, 1887-1917. Champaign, IL: University of Illinois Press. 
Ferguson-Colvin, Kristin M., and Elaine M. Maccio. 2012. “Toolkit for

Practitioners/Researchers Working with Lesbian, Gay, Bisexual, Transgender, and Queer/Questioning (LGBTQ) Runaway and Homeless Youth.” New York: National Resource Center for Permanency and Family Connections, Silberman School of Social Work. http://www.hunter.cuny.edu/socwork/nrcfcpp/info_services/download/LGBTQ\%20HRY \%20Toolkit\%20September\%202012.pdf.

Galusca, Roxana. 2012. "Slave Hunters, Brothel Busters, and Feminist Interventions: Investigative Journalists as Anti-Sex-Trafficking Humanitarians." Feminist Formations 24 (2): $1-24$.

Gordon, Derrick M., and Bronwyn A. Hunter. 2013. “Invisible No More: Creating Opportunities for Youth Who are Homeless." New Haven, CT: The Consultation Center, Yale University School of Medicine. http://www.pschousing.org/files/InvisibleNoMoreR eport.pdf.

Gulati, Giresh J. 2011. "News Frames and Story Triggers in the Media's Coverage of Human Trafficking." Human Rights Review 12: 363-79.

Hoang, Kimberley Kay. 2014. "Competing Technologies of Embodiment: Pan-Asian Modernity and Third World Dependency in Vietnam's Contemporary Sex Industry." Gender \& Society 28 (4): 513-36.

Hoang, Kimberley Kay, and Rhacel Salazar Parrenas. 2014. Human Trafficking Reconsidered: Rethinking the Problem, Envisioning New Solutions. New York: IDebate Press.

Karalekas, Nikki. 2014. "Is Law Opposed to Politics for Feminists? The Case of the Lusty Lady." Feminist Formations. 26 (1): 27-48. 
Kempadoo, Kamala. 2001. "Women of Color and the Global Sex Trade: Transnational Feminist Perspectives.” Meridians 1 (2): 28-51.

Lawston, Jodie M., and Erica R. Meiners. 2014. "Ending our Expertise: Feminists, Scholarship, and Prison Abolition." Feminist Formations 26 (2): 1-25.

LeBaron, Genevieve and Roberts, Adrienne. 2010. “Toward a Feminist Political Economy of Capitalism and Carcerality.” Signs 36 (1): 19-44.

Lewis, Ruth, and Susan Marine. 2015. "Weaving a Tapestry, Compassionately: Toward an Understanding of Young Women's Feminisms.” Feminist Formations 27 (1): 118-40.

National Center on Family Homelessness. 2014. America's Youngest Outcasts Fact Sheet. Waltham, MA: American Institutes for Research.

National Coalition for the Homeless. 2009. LGBTQ Homelessness. Washington, DC.

Ray, Audacia. 2007. Naked on the Internet: Hookups, Downloads, and Cashing in on Internet Sexploration. Berkeley, CA: Seal Press.

Reger, Jo. 2014. "Micro-Cohorts, Feminist Discourse, and the Emergence of the Toronto SlutWalk." Feminist Formations 26 (1): 49-69.

Rosen, Eva and Sudhir Alladi Venkatesh. 2008. “A 'Perversion’ of Choice: Sex Work Offers Just Enough in Chicago's Urban Ghetto.” Journal of Contemporary Ethnography 37 (4): 417-41.

Sassen, Saskia. 2002. “Women’s Burden: Counter-Geographies of Globalization and the Feminization of Survival.” Nordic Journal of International Law 71: 255-74.

Schwarz, Corinne and Hannah Britton. 2015. "Queering the Support for Trafficked Persons: LGBTQ Communities and Human Trafficking in the Heartland.” Social Inclusion 3 (1): $63-75$. 
Shrage, Laurie. 2012. "Feminist Perspectives on Sex Markets." The Stanford Encyclopedia of Philosophy Archive, last modified July 11, 2012. http://plato.stanford.edu/archives/win2014/entries/feminist-sex-markets

Soderlund, Gretchen. 2005. "Running from the Rescuers: New U.S. Crusades Against Sex Trafficking and the Rhetoric of Abolition.” NWSA Journal 17 (3): 64-87.

Spencer, Jon, and Rose Broad. 2012. “The 'Groundhog Day' of the Human Trafficking for Sexual Exploitation Debate: New Directions in Criminological Understanding." European Journal on Criminal Policy and Research 18 (3): 269-81.

Srikantiah, Jayashri. 2007. "Perfect Victims and Real Survivors: The Iconic Victim in Domestic Human Trafficking Law.” Boston University Law Review 87: 157-211.

Stienstra, Deborah. 1996. "Madonna/Whore, Pimp /Protector: International Law and Organization Related to Prostitution." Studies in Political Economy 51: 183-217.

Tilly, Charles, and Lesley J. Wood. 2012. Social Movements 1768-2012. 3rd ed. Boulder, CO: Paradigm Publishers.

US Census Current Population Survey. 2016.. "Income and Poverty in the United States: 2015." https://www.census.gov/content/dam/Census/library/publications/2016/demo/p60256.pdf.

US Department of Health and Human Services. 2014. Adoption and Foster Care Analysis and Reporting System (AFCARS) Report, FY 2013. http://www.acf.hhs.gov/sites/default/files/cb/afcarsreport21.pdf.

US Department of Homeland Security. 2015. Immigration and Customs Enforcement Immigration Removals. http://www.ice.gov/removal-statistics/. 
US Department of Justice. 2011. "Characteristics of Suspected Human Trafficking Incidents, 2008-2010.” http://bjs.ojp.usdoj.gov/content/pub/pdf/cshti0810.pdf.

Weitzer, Ronald. 2012. "Sex Trafficking and the Sex Industry: The Need for Evidence-Based Theory and Legislation.” The Journal of Criminal Law \& Criminology 101 (4): 1337-70.

—. 2014. "New Directions in Research on Human Trafficking." The ANNALS of the American Academy of Political and Social Science 653: 6-24. 